Accepted author manuscript version reprinted, by permission, from Sociology of Sport Journal, 2018, 35 (4): 386-393, https://doi.org/10.1123/ssj.2017-0033. @ 2018 Human Kinetics, Inc.

\title{
Ricky and Stick Icky: Marijuana, Sport, and the Legibility/lllegibility of Black Masculinity
}

\author{
Nikolas Dickerson \\ University of Lincoln
}

Dept. of Sport and Exercise Science, University of Lincoln, Lincoln, United Kingdom. Address author correspondence to Nikolas Dickerson at ndickerson@lincoln.ac.uk.

In November of 2016, California, Maine, Massachusetts and Nevada legalized recreational marijuana, while Arkansas, Florida, Montana, and North Dakota passed legislation to allow for the medicinal use of marijuana. As of July 2017, 37 states and the District of Columbia having legislation that allows for the medicinal or recreational use of marijuana. Coinciding with the increasing legalization of marijuana, at both the recreational and medical level, $61 \%$ of Americans are now in favor of marijuana legalization (Ingraham, 2016). The changing attitudes towards the legalization of the plant and legalization of marijuana in certain states suggests that prohibition of marijuana may be coming to an end. At the same time, current attorney general, Jeff Sessions is currently advocating to repeal and outlaw legal marijuana. Thus, despite the growing challenges to marijuana prohibition there is still a large effort to keep the plant illegal. These tensions highlight the contradictory and complex narratives marijuana is engulfed in. 
After all, in the United States, marijuana is legal for recreational use, legal for medicinal use, and a source of comedy in stoner films such as, Cheech and Chong: Up in Smoke, Half Baked, Harold and Kumar Go to White Castle, but also illegal at the federal level in all 50 states. The hazy landscape of marijuana reform creates a context where marijuana use is legal for some but illegal for others, and this contradiction is clearly visible within racial disparities of arrest rates for marijuana. A 2013 American Civil Liberties Union (ACLU) report documented, that while marijuana use among blacks and whites is relatively the same, blacks are almost four times as likely to be arrested for marijuana possession (http://www.aclu.org/files/assets/acluthewaronmarijuana-rel3.pdf). In Colorado, where marijuana is legal for recreational and medicinal use, the arrest rates for whites between the ages of 10-17 has fallen by almost 10 percent from 2012-2014, while the arrest rate for Latino and black teens has risen by 20 percent and 50 percent respectively (Markus, 2016). Thus, while the legalization of marijuana has opened space to conceptualize marijuana outside negative stereotypes, racial minorities are still suffering at a higher rate than white Americans when it comes to the enforcement of the prohibition of the plant.

The inequities within the current enforcement of marijuana prohibition stem from drug policies that are designed to control groups that are situated as dangerous or a threat to general society (Betram et al., 1996). Regarding marijuana, the perceived need to safeguard society from marijuana users is embedded within discourses of race, gender, and nation. During the 1930s, the Drug Enforcement Agency (DEA) used yellow journalism and propaganda films that drew on fears of the racialized body by depicting black and Mexican marijuana users as violent, criminal, and hyper-sexual to build support for marijuana prohibition (Provine, 2007). White middle-class women were also situated within these narratives to further highlight the danger of marijuana and 
the racialized other. Anti-marijuana propaganda characterized white women as innocent individuals who were susceptible to marijuana pushers, and once under the influence of the plant, these women could easily violate norms of sexual respectability by having sex with men of color (Boyd, 2008).

More specifically, these potential acts of sexual deviance were mapped onto nationalistic and racialized discourses about the superiority of the white race, and white women birthing mixed race babies threatened these narratives (Boyd, 2008). The construction of these early antimarijuana narratives relied on dehumanizing representations of racial minorities and women. Black bodies were portrayed as either a threat to the social order or to the purity of the white race through sexual transgressions with white women. These narrow constructions of marijuana users would expand during the 1960s. White marijuana users were depicted as young individuals who were good people that engaged in a minor transgression by smoking marijuana in popular culture (Himmelstein, 1983). Such depictions, coincided with the changing of a marijuana possession charge from a felony to a misdemeanor (Gerber, 2004). The shift in meanings of the marijuana user-as well as the changes in criminal policy-symbolizes the humanity granted to white marijuana users, a fate that was not granted to racial minorities.

In 2017, there is still a discrepancy regarding which bodies can use marijuana that is heavily influenced by relations of power. To explore the shifting and contradictory narratives of marijuana in the US, I draw on the experiences of former National Football League (NFL) player Ricky Williams. Birrell \& McDonald (2000) argue that critical analysis of narratives surrounding athletes offers unique points of access to the construction of meaning and power relations within larger society (see also McDonald \& Birrell, 1999). Thus, Williams is the entry point to larger discourses of race and masculinity within sport and general society. While, many professional 
athletes have used or tested positive for marijuana (Michael Phelps, Tim Lincecum, Randy Moss, Joakim Noah, Ross Rebagliati, among many others) Williams has been referred to as "America's most infamous stoner athlete" (Bishop, 2016, p. 50). In part, this description is connected to the popular belief that he retired in 2004, during the prime of his career, to travel the world and smoke pot (Stoda, 2006; Wilbon, 2005). Right before training camp, Williams was suspended for testing positive for marijuana. Williams then decided to retire and spend time traveling through Asia and Australia, which only perpetuated the belief he was more interested in pot than football. Williams returned to the NFL in 2005, and was subsequently suspended for marijuana use again in 2006 and 2007. Williams's marijuana use, retirement, and return to the NFL in 2006 resulted in several complex and contradictory narratives within the sport media, and it is these diverse range of discourses that make him a pertinent point of exploration. For example, by retiring early, Williams was situated within narratives that framed him as selfish (Attner, 2004; Stoda, 2006), and a quitter (Bohls, 2008; Kaufman, 2004). The fact that his early retirement was preceded by a positive marijuana test also helped perpetuate these negative constructions of Williams, as he became the "Bob Marley of football" (Saraceno, 2005), someone that just wanted to travel and smoke (Wilbon, 2005), and a bad role-model because of his pot use (O’Neil, 2004). Some journalists downplayed the seriousness of Williams's marijuana use, noting marijuana use was not as serious as the use of steroids (Wyld, 2007), marijuana use was banal in general (Radawanski, 2006), and Williams's marijuana use paled in comparison to violent criminal activity (Myers, 2007). Additionally, Williams's own discussion of his marijuana use and retirement offer another way to understand these acts: "I didn't quit football because I failed a drug test. I failed a drug test because I was ready to quit football” (Myers, 2004, p. 102). 
Ricky Williams is thus ensnared within several competing discourses about marijuana use and sport. More so, these narratives about Williams cannot be separated from larger understandings of race and gender, much like contemporary marijuana policies in the United States. As of July 2017, 29 states and the District of Columbia have legalized medical marijuana, while eight states and the District of Columbia have legalized recreational use of marijuana. Yet, marijuana is still illegal at the federal level, and it is racial minorities who suffer the most from this prohibition, as they are arrested almost four times more than whites-despite no greater use (Nadelman, 2010). Thus, Williams is situated as a repository of important narratives of black masculinity in relation to sport, marijuana, and the policing of black bodies.

To make sense of the variety of meanings produced concerning William's marijuana use, I draw on several forms of media. The analysis of Williams's marijuana use and retirement includes the printed press coverage of these incidents, and the documentaries Run Ricky Run (2010, and A football life: Ricky Williams (2014). I read Williams's marijuana use as a "text", to gain insight into the racialized and gendered understandings of marijuana use in the NFL and larger society (Birrell \& McDonald, 2000; McDonald \& Birrell, 1999). I argue that narratives that countered the framing of Williams's marijuana use as selfish failed to gain traction within the sport media due to the illegibility of these performances of black masculinity. In other words, the narrow representations of black masculinity within popular culture rendered the more complicated identity of Williams unrecognizable (Neal, 2013). Thus, such illegibility lead to the discursive construction of Williams as a stereotypical selfish black athlete overshadowing more radical discourses of black masculinity.

\section{Illegible and Legible Blackness}


Mark Anthony Neal (2013) uses the term legible black masculinity to refer to easily recognizable performances of black men in popular culture such as, the criminal/thug or individuals that have fully assimilated to white middle-class cultural norms (The Bill Cosby Show). These conceptualizations of black masculinity become legible through their constant reproduction within popular culture. Within sport, the most legible forms of black masculinity are the good black (assimilated to white cultural norms) and the bad black (criminal, egotistical, individualistic) (Wilson, 1997). These representations provide relief to US citizens as they either reaffirm that black bodies should be policed and surveyed, or present a black body that is safe for consumption as it has been stripped of any dangerous signs of blackness (Neal, 2013). Maintenance of these limited versions of black masculinity work to sustain the racial hierarchy while also dehumanizing the black body.

While there are several scholars that examine the larger issues of race and understandings of being human (see Spillers, 1997; Weheliye, 2014), I use the term dehumanizing to refer to representations of black masculinity that do not account for the complexities and emotional experiences of black men. The limiting and dehumanizing constructions of legible black masculinities are perpetuated through color-blind ideology. Color-blind ideology is a modern form of racism that uses non-racial dynamics to explain racial inequalities (Bonilla-Silva, 2010). Color-blind ideology divorces racial inequality from historical and contemporary racist practices, and instead uses racialized beliefs such as African Americans are criminal or lazy to explain racial inequity. Legible forms of black masculinity help sustain this power structure, as successful blacks can be used as an example that systematic racism no longer exists, and that issues of race no longer matter. At the same time, the criminal black is used to justify the surveillance of black bodies and racist practices such as, the prison industrial complex (Neal, 
2013). In an era, where overt forms of racial discrimination are not as acceptable as in previous eras, legible forms of black masculinity are one way in which systematic forms of racial discrimination are kept intact.

In relation to the use of illegal drugs, mediated representations of this behavior have primarily depicted racial minorities as dangerous drug users that pose a threat to the moral order of society (Boyd, 2002). These representations cannot be separated from the ways in which the prohibition of illegal drugs such as marijuana are enforced. Members of poor urban neighborhoods are surveyed at a higher rate than those who live in the suburbs because of differences in how drug deals are arranged in these two areas (Alexander, 2010). In the suburbs or on college campuses, drug deals often happen between friends in private homes or apartments, while in the inner city they often happen on the street (Provine, 2007). This exposure of course makes it easier to police the inner city, and makes this area and the people who inhabit it, the ones who suffer the most from the War on Drugs (Betram et al. 1996). These racialized and classed discrepancies are also reinforced through actual legislation.

The legible black body is consistently used to justify the policing, surveillance, and the incarceration of black men (Neal, 2013). Contemporary policing practices and policies such as stop and frisk make it legal for police officers to stop and search anyone on the street in search of drugs and weapons (Alexander, 2010). Most people do not know they legally have the right to refuse these searches and the absence of this knowledge helps to perpetuate more drug arrests. Furthermore, as Michelle Alexander (2010) argues minority bodies, particularly the bodies of black men, have come to connote criminality, and hence are more often the subject of these random stops and frisks. The perceived innate link between the black body and criminality is also reproduced through representational practices within the sport media. 
Philip Cunningham (2009) argues that overrepresentation of black male professional athletes that have committed high profile crimes such as the dog-fighting ring funded by Michael Vick, the nightclub gun fight of Adam "Pacman" Jones, and other such activity has led to the infusion of the black athlete and the criminal. More specifically, the overrepresentation of black athletes as criminals has rendered the two synonymous within the public imagination. The disproportionate attention given to black athletes who have committed crimes, in relation to white athletes who have committed similar acts, only exacerbates the connection between the black body and criminality (Ferber, 2007). This representation of the black male body has deep historical roots. Historical representations of black men as violent, criminal, and hypersexual have been used to justify dehumanizing and disciplining practices such as slavery, police brutality, and mass incarceration (Collins, 2004). However, representations of the marijuana using athlete tend to focus on attributes of morality, as opposed to physical violence.

Jonothan Lewis \& Jennifer Proffitt's (2012) “Bong hits and water bottles: An analysis of news coverage of athletes and marijuana use" is a rare piece that examines media coverage of both white and black athlete's marijuana usage. They found that the printed press tended to downplay the marijuana use of white athletes (Ex. Michael Phelps) and use these athletes' transgressions as an opportunity to discuss the irrationality of marijuana laws. However, the press's discussion of the marijuana use of black athletes (Ex. Michael Vick) was often used as an opportunity to vindicate a pattern of negative behavior, and the ineffectiveness of marijuana legislation was omitted. On a similar note, David Leonard (2017) argues, that black athletes such as Williams, are represented as selfish players who lack self-control or discipline in their inability to refrain from smoking pot, while the use of marijuana by white athletes in mostly white sports like snowboarding is often celebrated and normalized. Thus, press coverage of the 
marijuana using black athlete has worked to constitute and preserve the criminal and selfish label as a legible form of black masculinity.

Kyle Kusz (2007) argues the selflessness and morality of white athlete such as Pat Tillman is sustained through the constant juxtaposition with black athletes that are labeled as selfish and attention seeking (see also Andrews 1996b; Cunningham, 2009; Ferber, 2007). The framing of black athletes as selfish and attention seeking often emerges from these athletes challenging the status quo. Black athletes like Allen Iverson that are not subservient and seen as challenging the status quo within sport are often labeled as disrespectful and in need of civilizing (Ferber, 2007). In this manner, the body of the criminal black athlete and selfish black athlete are connected. Both are a threat to violate the social order and therefore need to be disciplined and controlled (Leonard \& King, 2011).

The overrepresentation of black athletes as selfish works to sustain beliefs that the black athlete is immoral compared to their white counter-parts, but this racialization process is obscured because it is explained through non-racial dynamics (Bonilla-Silva, 2010). For these myths to be sustained, there needs to be the concept of the good black to be juxtaposed against the criminalized black body. The commodification process is a central site for the representation of the good black. The commodification of black athletes such as Tiger Woods or Michael Jordan help to reinforce color-blind ideology, as these athletes become symbolic of a post-racial America where success is possible through hard work (Ferber, 2007).

Hence, both forms of legible black masculinities, the criminal and the assimilated black, are needed to sustain current racial ideology. Representations of the black criminal athlete sustains beliefs that the black body should be feared and surveyed, while the assimilated and subservient black is used as proof that racial barriers no longer exist if individuals adopt proper 
values (Neal, 2013). At the same time, even though the commodified black athlete is used as a sign of racial progress, this athlete is still often reduced to their body. Gamel Abdel-Shehid (2005) argues that as the black body becomes increasingly relied upon to sell products it becomes more difficult to understand the black body outside of the attributes it is asked to sell such as, power, strength, sex, and speed. Therefore, whether the black body is labeled as criminal or selfish or used to sell products, discourses of fear, envy, and desire surrounding what the black body can do become the familiar tropes of black masculinity.

Ricky Williams presents a conundrum as he is situated within contradictory discourses of the good black, bad black, as well as a person who cannot be defined. Bryant Keith Alexander (2006) argues that without the proper cultural toolboxes we are unable to make sense of unfamiliar cultural groups (see also Andrews, 1996b). Therefore, the repeated discursive constructions of black masculinity within a narrow dichotomy does not give those that are unfamiliar with the African American experience the toolbox to understand someone like Williams whose attributes are situated across numerous discourses. By re-reading the narratives surrounding Williams's retirement and marijuana use this project seeks to demonstrate how normalized discourses of race and masculinity are constructed (Abdel-Shehid, 2005; McDonald, 2002; Oates, 2014), while also opening a larger discursive space regarding what it means to perform black masculinity (Neal, 2013).

\section{Methods}

Susan Birrell and Mary McDonald (2000) argue that reading a sport celebrity or athletic event like a "text" offers a unique point of access into understanding relations of power within our larger social world. This approach to critically examining sport relies on an analysis of narrative. Texts such as film, newspapers, and television are ideologically coded and therefore 
work to construct discourses about race, gender, the nation, and sexuality (McDonald \& Birrell, 1999). In this analysis, I focus on the ways both issues of race and gender inform the various narratives of Ricky Williams. As Birrell \& McDonald (2000) argue this is necessary because lines of power do not work independently of each other and therefore must be understood through the complex way race, gender, sexuality, etc. work together.

Newspaper articles and documentaries were examined in this study to gather insight into how race and gender informed the narratives of Williams. The databases Google, Lexis Nexis, and Sport Discus were used to search for articles between 2004-2012. These three databases were chosen to gather a substantial and variety of printed press accounts of Williams's marijuana use and retirement. Given the high-profile status of Williams, and his abrupt retirement, it was likely that these events would get a lot of press coverage. Thus, Lexis Nexis was used to gather newspaper sources, while Google and Sport Discuss were used to gather articles from other printed press sources such as, Sports Illustrated and The Sporting News. Each database was searched via key words such as, Ricky Williams \& Marijuana use, Ricky Williams and pot, and Ricky Williams retirement. Only articles that discussed Williams's marijuana use, suspensions, or retirement were included. Articles that simply reported that Williams had been suspend or retired were excluded from analysis, as they just reported this information and did not make attempts to make sense of the events. In total, 55 articles met the previously mentioned criteria.

The timeline of this analysis is from 2004-2014. The year 2004 is the starting point for this project because it coincides with Williams first retirement and publicized marijuana use. Williams retired in 2012, but the extended timeline allows for the inclusion of ESPN's 30 for 30 documentary, Run Ricky Run, and NFL films A football life: Ricky Williams. The inclusion of these documentaries allowed for an intertextual examination of Williams's marijuana use. The 
texts in question are all interrelated, and their meaning is produced through the ways they interact and reference each other. As a result, the inclusion of these end-of-career documentaries help gather an understanding of Williams's public biography, as they help create meaning about Williams through their interactions with other texts about the former player (Birrell, 2007).

Run Ricky Run, was released on April 27, 2010 and was directed by Sean Pamphilon and Royce Toni. The film was aired on ESPN and was a part of a series of documentaries made to celebrate the $30^{\text {th }}$ anniversary of ESPN, while shedding light on important sport stories that had been forgotten (Vogan, 2012). This film was released during Ricky Williams second to last season in the NFL and three years after his one-year suspension from the NFL. A football life is an episodic documentary series where each episode focuses on the life of one player, coach, or owner. The episode featuring Ricky Williams was part of the fourth season. Both documentaries cover his multiple suspensions, marijuana use, and discuss his yoga practices and holistic healing training.

In both the printed press articles and the documentaries my analysis focuses on what was emphasized, obscured, and left out of the larger narratives of Williams's marijuana use and retirement. Williams's marijuana use and retirement is analyzed to uncover the ideological consequences of the varying narratives of these events. Larger societal understandings of race and gender were used to analyze these competing narratives (Birrell \& McDonald, 2000). Williams's performance of black masculinity was illegible to most sport journalists, as Williams was repeatedly characterized as strange and abnormal for a football player. Williams's illegible black masculinity, functioned as a catalyst for the re-articulation of more legible forms of black masculinity. Specifically, sports journalists often used Williams's marijuana use and retirement 
to label him as selfish and ungrateful, as opposed to exploring more complicated understandings of these events.

\section{The Strangeness of Ricky Williams}

Williams's marijuana use and retirement oscillate between an array of complex and often competing discourses of race and masculinity (Andrews, 1996). On one hand, his marijuana use and retirement are thought to be the epitome of selfishness (Attner, 2004; Bohls, 2008; Wood, 2005), while other journalists dismiss his marijuana use as a minor transgression compared to steroids and criminal violence (Myers, 2007; Wyld, 2007), and Williams presents a narrative of a player struggling mentally and physically who then uses a positive marijuana test to help him step away from the game of football (Pamphilon \& Toni, 2010). The dominant narrative about Williams tends to focus on the perceived selfishness of his actions. However, this legible form of black masculinity relies on other narratives that situate Williams as someone who cannot be defined.

For instance, in 1999, before the start of his rookie season, Ricky Williams and his coach, Mike Ditka, posed for the cover of ESPN the Magazine. This cover depicted them as bride and groom with Williams in a wedding dress and Ditka in a tuxedo. This cover photograph is often used as a reference point signifying the illegibility of Williams. For example, Dan Daly (2004) of The Washington Times states,

After the Williams-Ditka nuptials, it hardly seemed strange at all that Ricky would conduct postgame interviews with his helmet on. Nor was it the least bit surprising when he tested positive for marijuana. The guy had to be on something, right? (p. C01) 
This short quote exemplifies the difficulties the mainstream press had in trying to make sense of Williams. In this case, it is Williams' violation of masculine norms by wearing a wedding dress that is subsequently used to explain other "odd" behavior. Marijuana is also used as explanation of why a male football player would pose in a wedding dress and other behavior that falls outside of the norm.

Yet, while the Williams and Ditka nuptials are marked as unusual, in many ways it is symbolic of traditional assumptions about black and white men in sport. The black male body has been continuously constructed as violent, animalistic, and hypersexual to justify control, regulation, and surveillance of the black body (Collins, 2004). Consequently, the untamed black body is constituted as in need of discipline. In the world of sport, it is often the white male coach that has symbolically served as the figure to rule over the undisciplined black male, and it is through the acceptance and embracement of this role that the black male athlete is accepted and seen as non-threatening (Ferber, 2007). Thus, when he poses as the bride, Williams is submitting to control of the white male authority figure by occupying the subservient role of the bride in traditional norms of gender and heterosexuality. Thereby the photo works to symbolically reinforce his subservient role in racial hierarchy of professional sport and society in general.

Ricky Williams's strangeness is marked by journalist through his performances of gender. 'Ricky's personality is the furthest thing you'd expect from a football player. He's more like a writer, a poet" (Colbourn, 2006, p. C04). Williams is also more like a "bohemian" (Silver et al., 2004), or Henry David Thoreau (Wilstein, 2004). Additionally, the documentary A football life: Ricky Williams draws on this connection by opening the film with a shot of Williams in front of a statute of the artist, Rembrandt. These characterizations discursively construct 
Williams outside of the boundaries of hegemonic masculinity, as they emphasize emotion and the cerebral instead of physicality. More so, these attributes situate Williams beyond the borders of legible black masculinity, as they do not reduce Williams to the physical outputs of his body.

Rather, labels such as, bohemian, writer, artist, or poet connote understandings of intellect, whiteness, and emotional sensitivity. More so, descriptions such as, bohemian or Henry David Thoreau also signify anti-establishment political viewpoints, a stance that is often demonized within sport, particularly for black athletes (Collins, 2004). Hence, these narratives that place Williams outside legible understandings of black masculinity help perpetuate characterizations such as, Williams is "someone who cannot be defined" (Fitzgerald, 2006, p. B9), quirky (Weisman, 2004), and an enigma (Kernan, 2004). When Williams is labeled as an enigma or someone that cannot be defined, this discursive practice redraws the boundaries of legible black masculinities. There is no attempt to use descriptors such as bohemian or poet to expand notions of black masculinity. Instead, these labels are used as evidence that Williams falls outside the boundary of black masculinity and hence verifying the binary of legible black masculinity.

\section{Constructing the bad black}

Williams's illegibility is perpetuated by markers of gender that emphasize sensitivity and intellect situating him outside the boundaries of dominant discourse of black masculinity. Williams's illegible blackness, combined with his marijuana use and early retirement, create a context for the reproduction of narratives of legible black masculinity. Williams becomes the bad black through the positioning of his marijuana use and retirement as selfish acts. For example, Paul Attner (2004) states 
he has always been one of the most selfish, unpredictable, purposely bizarre and more than slightly off-kilter athletes of recent times-a man who doesn't think or act conventionally or care for one mini-second how his behavior and decision might affect anyone around him (p. 44)

In the case of this critique, Attner (2004) is unable to see Williams as an individual who has certain needs and the right to make his own decisions. Instead, more importance is placed on how Williams' decision to retire would impact his teammates and the larger Dolphins organization (see also Bell, 2004; Bohls, 2008; Woods, 2005).

This thread is picked up when Williams attempted to return to the NFL. Randy Rorrer (2005) of the Dayton Beach News Journal argues, that Williams was a quitter and couldn't be trusted. Greg Stoda (2006), of The Palm Beach Post, states Williams “doesn't care about anybody except Ricky Williams" and it is because of this selfish attitude that "Williams is exactly what the Dolphins don't need" (p. 1C). These discourses fail to engage with any discussion of why retirement might be good for Williams, and instead focus on the perceived violation of team dynamics and thus selfish actions Williams participated in by walking away from the game.

Williams discussed his early retirement in, A Football Life, mentioning that he began to see his own mortality due to the abuse his body was taking playing in the NFL (NFL Films, 2014). Furthermore, Williams later revealed his ambivalence toward his football career stating "If I was excited about playing, I wouldn't have been smoking dope" (Crouse, 2004, p. 1B). Williams adds to this narrative in a later segment in A Football life. He admits to wanting to retire before the 2003 season, but says, "he chose against himself and decided to keep 
playing". He also admits to not being that invested in the NFL. Williams frames his decision of going onto the NFL not as a goal, dream, or something that he was heavily invested in, but rather as just something you do after winning the Heisman trophy (NFL Films, 2014). In this instance, Williams offers some insight into how legible and illegible forms of black masculinity may impact black men.

The inability of Williams to envision anything else to do with his life besides play professional football hints at the limited framework black men may have of what is possible in their lives. In fact, bell hooks (2004) argues that the predominance of limited and negative stereotypes that circulate about black men over determines the identities that black men can create for themselves. Williams's own narratives about becoming indifferent to football but not knowing what to do with himself are indicative of the illegibility of more complex representations of black masculinity. Yet, the dominant racial and gendered discourses of the NFL do not leave room for understandings of black men that may become indifferent to being successful at the sport of football.

Instead, given the white working class culture within the NFL that asks players to suppress their individualism and sacrifice their bodies for the collective (Andrews, Mower, \& Silk, 2011) combined with the disproportionate demonization of acts by black players that are perceived to be individualistic (Cunningham, 2009), Williams is easily situated as the bad black. Greg Cote (2007) of the Miami Herald, discussing Williams on National Public Radio (NPR), sums this up by stating

He's a man who has a lot going on in his life and sometimes manages to fit football in. And that's what people in football sort of can't fathom, is the idea that this guy is not as 
passionate about their beloved sport as they want him to be (quoted in Chadwick, 2007, II 3).

The legible scripts of black masculinity objectify black men and strip them of their agency and humanity. Therefore, as this quote highlights, it is difficult for the public and the sport media to comprehend a black male athlete engaging in acts to heal the body and mind, as opposed to harming their body and mind through the violent sport of football. More so, black athletes that are believed to violate the norms of sport to do things in their own way are routinely vilified (Lorenz \& Murray, 2011). Thus, to make sense of Williams, his decision to retire, is often transformed into to an act of selfishness. Without more complex scripts that account for the emotional complexity and humanity of black men, Williams's more complex emotional needs and interests are rendered illegible.

Williams decision to retire is further simplified through discussions of his marijuana use. For instance, in response to a former teammate of Williams contemplating Williams potential to go crazy, Greg Colbourn (2006) states "Williams did, mailing himself overseas and walking away from the NFL and millions of dollars. He preferred to regularly smoke marijuana like his hero, Bob Marley, and to search for the other side of himself' (p. C04). In this quote, Williams is marked as abnormal and his marijuana smoking is highlighted as a behavior that is synonymous with an irrational state of mind.

In the previous quote, Bob Marley is also reduced to a marijuana smoker, as opposed to a musician, political figure, and Rastafarian. The connection between Bob Marley and Ricky Williams is also illustrated through the following: "Ricky Williams, whose pot history is positively Marleyesque" (Perkins, 2005, p. E01) or Jon Saraceno (2005) calls Ricky Williams the "Bob Marley of football” (p.6C). In these one-liners, Bob Marley becomes a signifier of 
marijuana use and is reduced to one legible characteristic. These descriptions do not allow for any nuanced understandings of his marijuana usage, which when connected to Williams discounts the potential to understand Williams's usage of the plant outside of self-indulgence. For instance, Williams had a prescription for medical marijuana for his social anxiety issues, which he reported as being more effective than prescription drugs (Bennett, 2013). However, the inability to link Williams's marijuana use to anything other than self-indulgence then becomes another way to discursively construct him as the bad black.

\section{Making the illegible, legible}

While playing with the Toronto Argonauts, Williams was asked what he would do if he knew a teammate was using drugs, and his response offers a counter-narrative to his own treatment by the media:

I'm a guy who truly believes in to each his own. I smoked for a couple of years, but I wouldn't necessarily tell someone to smoke because it's obviously illegal and it's a drug. But if a teammate came up to me, I wouldn't berate him, yell at him or tell him he's a bad person. The problem is we always tell people what to do and not look at why they do it (Naylor, 2006, p.S.1)

There are a small number of journalists that attempt to empathize with Williams's decision making and praise his willingness to apologize to teammates and fans for the consequences of his early retirement (see Cote, 2008; Kernan, 2005; Maskke, 2004; Wilbon, 2005). Nonetheless, none of these articles engage with a narrative that presents marijuana use as something other than self-indulgence.

The ability to look past the act of marijuana smoking to answer the larger question of why does a person choose to use pot is incredibly relevant to the contemporary NFL. Former 
NFL players, such as Jamal Anderson, have estimated that during his playing days $40-50 \%$ of the league smoked, and Anderson believes about $60 \%$ of the league smokes marijuana currently (Freeman, 2015). Additionally, both current and former players are beginning to advocate for the use of marijuana to deal with chronic pain and concussions, because of its effectiveness over traditional painkillers (Bryant, 2013). For example, former NFL players such as Jim McMahon, Scott Fujita, and Brendan Ayanbadejo are advocating for the use of medical marijuana for players (O'Keeefe, 2016), while current player Eugene Monroe of the Baltimore Ravens recently donated $\$ 80,000$ towards medical research investigating the impact of medical marijuana on football players (Wood, 2016). Yet, to move forward with this, the players of the NFL would have to be understood as more than people who want to get high.

In other words, understandings of what it means to be marijuana user would have to be expanded for any sport league to accept the use of medical marijuana by their players. Waddington (2000) argues it is the illegality of recreational drugs such as marijuana, as well as fears about public sentiment that are the driving forces of sport organizations like the International Olympic Committee (IOC) banning the substance (see also Wenner, 1994). Issues regarding the representation of marijuana users becomes even more complicated with leagues like the NFL, given the racial make-up of the league. As, the problem of recreational drug use within sport is predominantly framed through the black body (King et al., 2014). However, more expansive narratives of black marijuana users are hindered by the dichotomy that exists between recreational drug use and sport.

CL Cole (1996) discusses the ways the popular press represents sport and gangs as oppositional entities competing for the souls of African American youth. She argues that the problem of gangs is made to matter through the constant juxtaposition with sport whereby there 
is a perceived inverse relationship. This relationship is framed through the perceived struggles for character and morality by black youth in the inner-city, and sport and gangs represent opposite ends of this battle for morality (Cole, 1996). Sport and recreational drug use, specifically marijuana can be thought of in a similar manner. Sport historically has been constructed as a site to build a sense of morality and counter the ills of society (Dyerson, 1998), while marijuana has often been constructed within prohibition circles as a substance that causes the user to slip into passive fantasy world (Himmelstein, 1983). Thus, while sport is meant to make the individual a healthy productive member of society, marijuana use makes the user passive and unproductive.

The perceived inverse relationship between recreational drug use and sport hinders the ability to understand the marijuana using athlete in a nuanced manner. This is particularly true for black athletes that use marijuana, as they tend to be framed in a negative manner compared to their white-counter parts (Lewis \& Proffit, 2012; Leonard, 2017). The limited framing of the black marijuana using athlete combined with narrow construction of the black male athlete in general, create a context where it is difficult to imagine alternative forms of black masculinity. The case of Ricky Williams helps to illustrate this larger point, as dominant discourses of Williams's marijuana use as selfish reinforces the sport/pot dichotomy, and highlight how the use of marijuana by the black body create a space for the reinforcement for legible black masculinities.

Yet, Williams's illegible performances of black masculinity offer a way forward. When presented with narratives of Williams that associate him with art, yoga, and disinterest in performing on the football field he represents a complexity that cannot be explained through the dominant representations of black men. Thus, while the use of marijuana by black athletes 
creates a context that is likely to perpetuate narratives of legible black masculinity, a critical analysis of these discourses creates a space for the articulation of more nuanced understandings of black men.

Ben Carrington (2010) argues that when black athletes themselves begin to critique forms of hyper-masculinity, they begin the work of forming less damaging forms of black masculinity (see also hooks, 2004). More so, the rejection of the white construction of the black athlete allows for a recovery of humanity that is denied through white patriarchal standards for black men. Revisiting some of the more marginalized narratives of Williams opens space for this type of work.

For example, during his first retirement Williams moved to California to study the holistic form of healing called Ayurveda. In Run Ricky Run, Williams mentions that after he moved to California, he lost interest in money and houses, and then says, "It hit me that I don't need money" (Pamphilon \& Toni, 2010). More so, in A football life: Ricky Williams, Williams discusses that his idea of success is based on gaining new knowledge and experiences, as opposed to racking up football stats (NFL Films, 2014). Williams's critique of the solitary pursuit of economic and athletic fame opens a space for alternative conceptions of what it means to be a black athlete. Placing emphasis on narratives such as this provide an opportunity to widen understandings of black masculinity, while also breaking links in the public imagination between the black body and anti-blackness (Neal, 2013).

Williams's discussion of his yoga practice is another example of how alternative discourses of black masculinity can be used to displace negative understandings of blackness. Per Williams, yoga helped him grow as a person and find balance in his life (Lefko, 2006), and it helped him learn how to relax without the help of marijuana (NFL Film, 2014). Additionally, 
through his experiences in becoming a yoga instructor Williams believes he concluded that his gift is to help people heal (Pamphilon \& Toni, 2010). Injecting these marginalized narratives into larger understandings of Williams help refute many of the damaging constructions of the black male athlete. The narratives of self-improvement, emotional management, and the assisting others disrupt discourses of the black athlete as animalistic, bound to physiological impulses, and selfish (Carrington, 2010). Thus, these marginalized narratives offer potential to open new and wider possibilities of what it means to be a black athlete and a black athlete that uses marijuana.

The most legible form of black masculinity, the black criminal, is produced and reproduced to sustain the racial hierarchies of the US (Neal, 2013). Therefore, the belief that the black body is criminal helps perpetuate the disproportionate policing of the black body in the enforcement of marijuana prohibition. Currently, black men are arrested at higher rates than whites despite no greater use (ACLU, 2013). In Colorado, a state where recreational marijuana is legal, the arrest rates for white teenagers have fallen while it has risen for black and Latino teens since the legalization of the plant (Markus, 2016). Re-articulating what it means to be a black body that uses marijuana is of critical importance. Expanding understandings of performances of black masculinity has the potential to humanize the black body. There is a need to make the illegible, legible. 
References:

Abdel-Shehid, G. (2005) Who da man?: Black masculinities and sporting cultures. Toronto: Canadian Scholars' Press Inc.

ACLU (2013) The war on marijuana in black and white: Billions of dollars wasted on racially biased arrests. Retrieved from https://www.aclu.org/files/assets/aclu-thewaronmarijuana rel3.pdf 
Alexander, B. (2006) Performing black masculinity: Race, culture and queer identity. Lanham, MD: Altamira Press

Alexander, B. (2012) The performative sustainability of race: Reflections on black culture and the politics of identity. New York, NY: Peter Lang Publishing, Inc.

Alexander, M. (2010) The New Jim Crow: Mass incarceration in the Age of colorblindness. New York, NY: The New Press

Andrews, D. (1996a) The fact(s) of Michael Jordan's blackness: Excavating a floating racial signifier. Sociology of Sports Journal, 13, 125-158

Andrews, D., Mower, R., \& Silk, M. (2012) Ghettocentrism and the essentialized black male athlete. In D. Leonard \& C. Richard King (Eds) Commodified and criminalized: New racism and African Americans in contemporary sport. Lanham, MD: Rowman \& Littlefield Publishers, Inc.

Andrews, V. (1996b) Black bodies-white control: The contested terrain of sportsmanlike conduct. Journal of African American Men, 2, 33-59

Attner, P. (2004 August 2) Williams is loyal only to himself. The Sporting News

Bayless, S. (2004 July 28) Williams, Russel not made for NFL. San Jose Mercury News, 1D 
Bell, J. (2004 October 7) Ex-teammates sour on Williams. USA Today, 09C

Bennett, D. (2013) Harm reduction and NFL drug policy. Journal of Sport and Social Issues, 37, 160-175

Bertram, E., Blachman, M., Sharpe, K., Andreas, P. (1996) Drug war politics: The price of denial. Berkley, CA: University of California Press

Birrell, S., \& McDonald, M. (2000) Reading Sport: Critical essays on power and representation. Boston: North Eastern Press

Birrell, S. (2007). Approaching Mt. Everest: On intertextuality and the past as narrative. Journal of Sport History, 34(1), 1-22.

Bishop, G. (2009 July 22) Hoping to heal others, and his image. The New York Times, P. 13

Bishop, (2016 July 18) Ricky Williams takes the high road. Sports Illustrated

Bohls, K. (2008 June 27) Williams ready to take football seriously again. Austin American Statesman, C01

Bonilla-Silva, E. (2010) Racism without racists: Color-blind racism \& racial inequality in contemporary America. Third Edition. Lanham, MD: Rowman \& Littlefield Publishers Inc. 
Boyd, S. (2002) Media constructions of illegal drugs, users, and sellers: A closer look at Traffic. International Journal of Drug Policy, 13, 397-407

Boyd, S. (2008) Hooked: Drug war films in Britain, Canada, and the United States. Toronto: University of Toronto Press

Bryant, H. (2013 December 10) Smoke Screen. ESPN. Retrieved from http://www.espn.com/nfl/story/_id/10110004/is-nfl-embrace-marijuana-espn-magazine

Carrington, B. (2001) Fear of a black athlete: Masculinity, politics and the body. New Formations: A Journal of Culture/Theory/Politics. 45, 91-110

Carrington, B. (2010) Race, sport and politics: The sporting black diaspora. London: SAGE Publications Ltd.

Chadwick, A. (2007, November 15). NFL reinstates Dolphins' free spirit running back. National Public Radio

Colbourn, G. (2006, May 29) An athlete with a poet's personality. Toronto Star.

Cole, C. L. (1996). American Jordan: PLAY, consensus, and punishment. Sociology of Sport Journal, 13(4), 366-397. 
Collins, P. (2004) Black sexual politics: African Americans, gender, and the new racism. New York, NY: Routledge

Cote, G. (2008 August 1) Redemption; Ricky Williams has returned hoping to clear his name and restore his football legacy. The Miami Herald, B12

Crouse, K. (2004 November 10) Ricky accepts being players' scapegoat. Palm Beach Post, 1B

Cunningham, P. (2009) “Please don’t fine me again!!!!!”: Black athletic defiance in the NBA and NFL. Journal of Sport and Social Issues, 33 (1), 39-58

Daly, D. (2004, July 27) ‘Truth' about Ricky is pretty strange. The Washington Times. C01

Dyerson, M (1998) Making the American team: Sport, culture, and the Olympic experience. Urbana, IL: University of Illinois Press

Ferber, A. (2007) The construction of black masculinity: White supremacy now and then. Journal of Sport and Social Issues, 31, 11-24

Fitz-Gerald, S. (2006 May 30) See Ricky run: No matter where Williams’ rambling ways take he running back, controversy has never been far behind. National Post (Toronto Edition), B9 
Fitz-Gerald, S. (2006 November 3) Fun and games: Outside of a smaller paycheque, the CFL was a perfect detour for Williams. National Post (Toronto Edition), S1

Frank, V. (2015 July 3) Recent suspensions show just out of touch NFL's marijuana policy is. Forbes. Retrieved from http://www.forbes.com/sites/vincentfrank/2015/07/03/recent suspension-shows-just-how-out-of-touch-nfls-marijuana-policy-is/\#30b4bb083260

Freeman, M. (2015 June 30) Banned, but bountiful: Marijuana coveted by NFL players as invaluable pain killer. Bleacher Report. Retrieved from http://bleacherreport.com/articles/2486218-banned-but-bountiful-marijuana-coveted-by nfl-players-as-invaluable-painkiller

Gerber, R. (2004) Legalizing marijuana: Drug policy reform and prohibition politics. Westport, CT: Praeger Publishers

Giambrone, A. (2014 December 1) Will congress let DC legalize pot? The Atlantic. Retrieved on January 28 from https://www.theatlantic.com/politics/archive/2014/12/will-congress-let washington-dc-legalize-weed/383276/

Himmelstein, J. (1983) The strange career of marijuana: Politics and ideology of drug control in America. Westport: CT, Greenwood Press.

hooks, b. (2004) We real cool: Black men and masculinity. New York, NY: Routledge 
Hyde, D. (2012 February 12) What's next?: Ricky Williams' world without football full of possibilities. Pittsburgh Post-Gazette, C2

Ingraham, C. (2016 March 25) Support for marijuana legalization has hit an all-time high. The Washington Post. Retrieved from https://www.washingtonpost.com/news/wonk/wp/2016/03/25/support-for-marijuana legalization-has-hit-an-all-time-high/

Johnson, G. (2006 September 23) The Ricky experience: Argos running back is one different kind of cat. The Calgary Herald, D1

Kaufman, I. (2004 November 28) Ricky Williams isn't worth the risk. The Tampa Tribune, 11

Kernan, S. (2005 July 30) Give Williams the benefit of the doubt. Daytona Beach News-Journal, 2D

King, S., Carey, R., Jinnah, N., Millington, R., Phillpson, A., Prouse, C., \& Ventesca, M. (2014) When is a drug not a drug? Troubling silences and unsettling painkillers in the National Football League. Sociology of Sport Journal, 31, 24-266

King-White, R. (2010) Danny Almonte: Discursive Construction(s) of (Im)migrant Citizenship in Neoliberal America. Sociology of Sport Journal, 27, 178-199

Kusz, K. (2007) From NASCAR nation to Pat Tillman: Notes on sport and the politics of white cultural nationalism in post 9/11 America. Journal of Sport and Social Issues, 31, 77-88 
Le Batard, D. (2004, July 30) Dolphins’ Williams chooses pot over NFL. The Miami Herald.

Lefko, P. (2006 May 30) Sorry to be so abstract: The Williams interview part 2: Yoga, religion and marijuana. The Toronto Sun, S4

Leonard, D., \& King, C. Richard (2011) Commodified and criminalized: New racism and African Americans in contemporary sport. Lanham, MD: Rowman \& Littlefield Publishers, Inc.

Leonard, D. J. (2017). Playing While White: Privilege and Power on and off the Field. Seattle, WA: University of Washington Press

Lewis, J., \& Proffitt, J. (2012) Bong hits and water bottles: An analysis of news coverage of athletes and marijuana use. Journal of Sports Media, 7, 1-21

Lorenz, S., \& Murray, R. (2011) The Dennis Rodman of hockey: Ray Emery and the policing of blackness in the great white north. In D. Leonard \& C.R. King (Eds) Commodified and Criminalized: New racism and African Americans in contemporary sports. Lanham, MD: Rowman \& Littlefield Publishers Inc.

Markus, B. (2016, June 29) As adults legally smoke pot in Colorado, more minority kids arrested for it. National Public Radio. Retrieved on August 20, 2016 from http://www.npr.org/2016/06/29/483954157/as-adults-legally-smoke-pot-in-colorado more-minority-kids-arrested-for-it 
Mascaro, C. (2014, May 14) NFL to change drug policy regarding marijuana use. Sports Illustrated. Retrieved on June 1, 2016 from http://tracking.si.com/2014/05/13/nfl-drug-policy-change-regarding-marijuana/

Maske, M. (2004 July 27) Williams joins runners who walked away. Washington Post, D01

McDonald, M. G. (1996). Michael Jordan's Family Values: Marketing, Meaning, and Post Reagan America. Sociology of Sport Journal, 13(4).

McDonald, M., \& Birrell, S. (1999) Reading sport critically: A methodology for interrogating power. Sociology of Sport Journal, 16, 283-300

McDonald, M. (2002) Queering whiteness: The particular case of the Women's National Basketball Association. Sociological Perspectives, 45, 379-396

McDonald, M. (2006) Beyond the pale: The whiteness of sport studies and queer scholarship. In J. Caudwell (Eds) Sport, sexualities, and queer/theory. New York, NY: Routledge

Messner, M. (2007) Out of play: Critical essays on gender and sport. Albany, NY: State University of New York Press

Myers, G. (2004, July 30) Ricky tells how career went to pot. New York Daily News. 
Myers, D. (2007, April 10). NFL should reinstate Ricky Williams. La Crosse Tribune,

Nadelman, E. (2010 December 27) Breaking the taboo. The Nation, 11-12

Naylor, D. (2006, May 30) Williams finds his karma: Running back lured to Toronto by chance to teach yoga for free. The Globe and Mail

Neal, M. A. (2013) Looking for Leroy: illegible black masculinities. NYU Press

NFL (2015) National Football League Policy and Program for Substance Abuse. Retrieved on April 15, 2016 from http://images.nflplayers.com/mediaResources/files/PDFs/PlayerDevelopment/201 0\%20Drug\%20Policy.pdf

NFL Films (2014 October 31) A football life: Ricky Williams [Television Broadcast]. United States: NFL Films

Oates, T. (2014) Failure is not an option: Sport documentary and the politics of redemption. Journal of Sport History, Summer 2014, 401-409

O’Keefe, M. (2004 October 10) The search for truth: Esquire scribe's big adventure with Ricky Williams. New York Daily News, 88 
O’Keefe, M. (2016 June 18) Jim McMahon, other NFL veterans push for marijuana as painkiller. New York Daily News, Retrieved on February 10, 2017 from http://www.nydailynews.com/sports/football/jim-mcmahon-nfl-veterans-push-marijuanapainkiller-article-1.2679087

O’Neil, D. (2004 August 8) A toke isn’t just a token thing. St Louis Dispatch, D02

Pamphilon, S., Toni. R. (Directors). (2010) Run Ricky Run [DVD]. United States: ESPN

Perkins, D. (2005, April 23) NFL drug pitch a scam. The Toronto Star.

Provine, D. (2007) Unequal under law: Race in the War on Drugs. Chicago: University of Chicago Press

Radwanski, A. (2006, May 12) Playing the hypocrisy game. The National Post. Retrieved on May 16, 2016 from www.lexisnexis.com

Rorrer, R. (2005 July 30) Underneath it all, has Ricky really changed? Once a quitter, always a quitter. Ricky Williams abruptly left the Miami Dolphins a year ago, sending the team into turmoil. A year later he's back at camp, but how should he be received by his teammates? Daytona Beach News-Journal, 2D

Saraceno, J. (2005, August 22) Catch the buzz on NFL pot scene. USA Today. 
Silver, M., Bechtel, M., Cannella, S. (2004 August 2) He’s going to Rickyland. Sports Illustrated, 101 (4), p. 23

Spillers, H. J. (1987). Mama's baby, papa's maybe: An American grammar book. diacritics, 17(2), 65-81.

Stoda, G. (2006 April 26) Suspended; Dolphins must quit habit of forgiving and forget. Palm Beach Post, 1C

The Province (2004 November 23) Retired RB studying to be a healer: From holes in the line to holistic medicine. The Vancouver Province, A52

Vogan, T. (2014) Keepers of the flame: NFL films and the rise of sport media. Urbana, IL: University of Illinois Press

Waddington, I. (2000) Sport, health and drugs: A critical sociological perspective. London: Routledge

Weheliye, A. G. (2014). Habeas viscus: Racializing assemblages, biopolitics, and Black feminist theories of the human. Duke University Press.

Weisman, L. (2004 July 26) Finally free, Dolphins tailback retires. USA Today, 01C

Wenner, L. (1994) Drugs, sport, and media influence: Can media inspire constructive attitudinal 
change? Journal of Sport and Social Issues, 18, 282-292

Wenner, L. A. (1995). The good, the bad and the ugly: race, sport and the public eye. Journal of Sport and Social Issues, 19(3), 227-231.

Wilbon, M. (2005 July 7) Iconoclastic backs leading parallel lives. The Washington Post, E01

Wilson, B. (1997) Good Blacks and Bad Blacks: Media construction of African-American athletes in Canadian basketball. International Review for the Sociology of Sport, 32, 177 189

Wilstein, S. (2004 July 27) What makes Ricky run?: Former Dolphin is searching for a truth that doesn't include football. The Vancouver Sun, E3

Wood, S. (2005 July 26) Dolphins greet Williams' return with caution. USA Today, 03C.

Wood, S. (2016 May 14) NFL tackle donates $\$ 80 \mathrm{~K}$ to Penn for marijuana research. Philadelphia Inquirer. Retrieved on February $5^{\text {th }}, 2017$ from http://www.philly.com/philly/health/20160514_NFL_tackle_donates_80k_to_Penn_for_ marijuana_research_on_players.html

Wyld, A. (2007, October 1) Reefer madness in NFL's drug rules. San Francisco Chronicle. Retrieved on May 15, 2016 from www.ebscohost.com 